\title{
Article \\ Enhancing the Reliability of Communication between Vehicle and Everything (V2X) Based on Deep Learning for Providing Efficient Road Traffic Information
}

\author{
Radwa Ahmed Osman ${ }^{1, *(\mathbb{D}}$, Sherine Nagy Saleh ${ }^{2, *}{ }^{\mathbb{D}}$, Yasmine N. M. Saleh ${ }^{3}$ and Mazen Nabil Elagamy ${ }^{2}$ \\ 1 Basic and Applied Science Department, College of Engineering and Technology, Arab Academy for Science \\ and Technology (AAST), Alexandria 1029, Egypt \\ 2 Computer Engineering Department, College of Engineering and Technology, Arab Academy for Science and \\ Technology (AAST), Alexandria 1029, Egypt; mazenelagamy@aast.edu \\ 3 Computer Science Department, College of Computing and Information Technology, Arab Academy for \\ Science and Technology (AAST), Alexandria 1029, Egypt; yasmine_nagi@aast.edu \\ * Correspondence: radwa.ahmed@aast.edu (R.A.O.); sherine_nagi@aast.edu (S.N.S.)
}

check for

updates

Citation: Osman, R.A.; Saleh, S.N.;

Saleh, Y.N.M.; Elagamy, M.N.

Enhancing the Reliability of

Communication between Vehicle and

Everything (V2X) Based on Deep

Learning for Providing Efficient Road

Traffic Information. Appl. Sci. 2021,

11, 11382. https://doi.org/10.3390/ app112311382

Academic Editor: Carla Raffaelli

Received: 23 October 2021

Accepted: 29 November 2021

Published: 1 December 2021

Publisher's Note: MDPI stays neutral with regard to jurisdictional claims in published maps and institutional affiliations.

Copyright: (c) 2021 by the authors. Licensee MDPI, Basel, Switzerland. This article is an open access article distributed under the terms and conditions of the Creative Commons Attribution (CC BY) license (https:/ / creativecommons.org/licenses/by/ $4.0 /)$.

\begin{abstract}
Developing efficient communication between vehicles and everything (V2X) is a challenging task, mainly due to the characteristics of vehicular networks, which include rapid topology changes, large-scale sizes, and frequent link disconnections. This article proposes a deep learning model to enhance V2X communication. Various channel conditions such as interference, channel noise, and path loss affect the communication between a vehicle $(V)$ and everything $(X)$. Thus, the proposed model aims to determine the required optimum interference power to enhance connectivity, comply with the quality of service (QoS) constraints, and improve the communication link reliability. The proposed model fulfills the best QoS in terms of four metrics, namely, achievable data rate $\left(R_{b}\right)$, packet delivery ratio (PDR), packet loss rate (PLR), and average end-to-end delay (E2E). The factors to be considered are the distribution and density of vehicles, average length, and minimum safety distance between vehicles. A mathematical formulation of the optimum required interference power is presented to achieve the given objectives as a constrained optimization problem, and accordingly, the proposed deep learning model is trained. The obtained results show the ability of the proposed model to enhance the connectivity between V2X for improving road traffic information efficiency and increasing road traffic safety.
\end{abstract}

Keywords: vehicle-to-everything; QoS; reliability; achievable data rate; deep learning; 1D-CNN

\section{Introduction}

The development of intelligent transport systems (ITS) is expected to project benefits such as traffic safety, lower congestion, various services offered to users while overcoming the disorganization and inefficiency of traditional systems [1]. According to the European Telecommunications Standards Institute (ETSI), ITS deploys innovative communication and relevant technologies into vehicles and infrastructures for efficient traffic management [2]. On-road interaction has different modes of communication, such as vehicle-to-vehicle (V2V), vehicle-to-infrastructure (V2I), Vehicle-to-network (V2N), and vehicle-to-pedestrian $(\mathrm{V} 2 \mathrm{P})$, which can altogether be referred to as vehicle-to-everything (V2X) [3,4].

V2X communication offers diverse applications and services with different quality of service (QoS) requirements (such as reliability, end-to-end latency, data rates, and throughput) $[2,5]$. V2X applications and services can be categorized as autonomous/cooperative driving, traffic safety, traffic efficiency, and infotainment. Autonomous/cooperative driving refers to the $\mathrm{V} 2 \mathrm{~V}$ communication among neighboring vehicles, which requires relatively high throughput and low latency [5]. Traffic safety involves the protection of vehicles and pedestrians, which can reduce the number and stern of inter-vehicle collisions, property damages, and road users' accidents. The traffic efficiency includes intersection timing 
coordination, source-to-destination route planning, and geographical location and road condition information sharing. Traffic efficiency has less stringent QoS requirements compared to autonomous/cooperative driving and traffic safety [5]. Infotainment refers to non-driving service information, which can include the location of hotels, gas stations, car rental locations, and entertainment services such as video streaming. Compared to the other V2X applications and services, infotainment requires minimum QoS requirements [5].

To enhance the quality of service (QoS) in a vehicular network, [6] introduced a method that employs a vehicle-to-vehicle (V2V) approach with cooperative communications to be combined with vehicle-to-infrastructure (V2I). They achieved closed-form expressions for significant QoS performance attributes such as packet delivery ratio (PDR), packet loss rate (PLR), average end-to-end-delay, outage probability, throughput, and energy efficiency, which were tested using different investigated transmission schemes. Additionally, [7] used device-to-device (D2D)-based V2X communication network to introduce an approach for power allocation with energy efficiency optimization (EEO), which enhanced spectral utilization, data rate, power consumption, traffic load, and EE. They succeeded to prove the algorithm and the mathematical framework of their approach using simulation results.

To improve the V2X utilities such as low latency and high reliability (LLHR) demands, [8] suggested a semi-persistent scheduling (SPS) strategy deploying millimeterwave and non-orthogonal multiple access. Through the combination of the power allocation process, beam division and user clustering process, and the vehicular user equipmentresource block (VUE-RB) matching process, their SPS strategy outperformed current schemes in terms of computational complexity, convergence, and stability. Afterward, an autonomous vehicle-to-everything (AV2X) model, which adopted a new optimization method to optimize the inter-vehicle position while communicating with AV or relaying information to everything was presented by [4] to reinforce the vehicular networks' connectivity. Their model's simulation results surpassed other models regarding PDR, PLR, average delivery latency (DL), and throughput, as they defined the best position of the relay-vehicle issue mathematically as a constrained optimization problem [4]. In addition, [4] showed enhancement in the network's average end-to-end delay and PDR by adopting V2V communication to identify the nearest vehicle to communicate with, which significantly reduced travel time by communicating the emergency message received instantly to all nearby vehicles on the route. To acquire different road traffic parameters, they applied an optimization technique. Finally, they used various simulation scenarios and assumptions to evaluate and examine the suggested traffic management strategy.

Recently, several applications have adopted deep learning as a powerful tool to create models that can be applied on devices in real life by learning from given parameters. The deep learning model can then produce a prediction according to the learned relation between parameters. Furthermore, the model can be re-trained from time to time to update its weights due to changes occurring in the environment and affecting the parameters. Among the diverse techniques of deep learning, several applications such as biomedical [9], electrical [10], and IoT [11] have applied the one-dimensional convolutional neural network $(1 \mathrm{D}-\mathrm{CNN})$ and proved its effectiveness.

A distributed deep learning (DDL) framework was developed by [12] to improve distributed non-convex constrained optimizations in wireless networks. To efficiently assign states based on local inspections, where multiple computing nodes interconnected by backhaul links, they used an infinite-capacity backhaul to facilitate nodes to communicate in a lossless way and a practical finite-capacity backhaul that uses distributed solvers supplied by quantizers to communicate over the capacity-limited backhaul. They also deployed deep neural networks (DNNs) to precisely approximate the solution's unknown computation, which results from the distributed nature and the non-convexity of the optimizations. To avoid V2X communication bottlenecks, [13] examined a dual optimization problem regarding resource allocation and transmission mode selection over $\mathrm{C}-\mathrm{V} 2 \mathrm{X}$ communications. To encounter the V2V pair's reliability and latency demands and expand the sum capacity of V2I users as well, they implemented a deep reinforcement learning 
(DRL)-based decentralized algorithm. A security-aware approach for enhancing SE and EE based on deep reinforcement learning (SEED) to improve spectrum efficiency (SE) and energy efficiency (EE) over a platooning network was presented by [14].

SEED deployed deep Q network (DQN) to convert the optimization problem to the transmission power and spectrum selections of V2X links. Simulation results showed that the efficiency of SEED is better than the DQN-wopa algorithm by $31.83 \%$ and better than the baseline algorithm by $68.40 \%$. Moreover, in [15], to improve the resource allocation issue for mixed distributed/centralized V2X communication systems under various network loading conditions, the authors introduced an approach using resource allocation mode selection and power control. They examined UE autonomous resource selection mode (distributed system) and scheduled resource allocation (centralized system) and attained a reliable matching between VUEs and their reuse PUE partners.

By developing a hopping strategy, which is based on the lowest propagation loss and considering the environment's effect Morocho-Cayamcela, [16] were able to enhance the reachability of multi-hop communications and environmental recognition. In 2021 to develop the performance of congestion control in CV2X sidelink, [17] implemented a DCC algorithm using DRL, which permitted the DRL agent to observe a CBR state to choose the packet transmission rate that boosts the reward of packet delivery rate (PDR) while preserving superior channel utilization. An interference avoidance DDL model for IoT and device to any destination communication was presented by [11] to improve EE and overall system throughput. Regarding root mean squared error and mean absolute error, their model outperformed the state-of-the-art regression benchmarks. This was achieved using the data produced by the Lagrange optimization technique to learn the model to predict CUE-IoTG, IoTG-CUE, BS-IoTD, and optimum IoTD-D distances for downlink and uplink data communication [11].

Deep learning is considered a strong candidate to solve many challenges that face the QoS enhancement of any wireless network system. Different interference control methods based on deep learning algorithms have been proposed in [11] and [18-28], to show how the implementation of deep learning algorithms enhances the system performance through different manners. Table 1 shows the difference between some of the recent deep learning interference control algorithms which enhance the system performance of different wireless network systems.

Table 1. Comparison between different recent proposed deep learning interference control for wireless networks.

\begin{tabular}{|c|c|c|}
\hline & Interference Control Technique & Network Performance Achievement \\
\hline [11] & $\begin{array}{l}\text { Interference avoidance is based on determining the optimum uplink } \\
\text { distance between IoTD-D and CUE-IoTG communication link and also } \\
\text { determining the optimum downlink distances between BS-IoTD and } \\
\text { IoTG-CUE communication link. }\end{array}$ & $\begin{array}{c}\text { Enhances the system's energy efficiency and } \\
\text { throughput. }\end{array}$ \\
\hline
\end{tabular}

A power allocation strategy is proposed based on extracting from the

[18] outdated channel information the local interference, this technique is known as called interference feature extractor aided recurrent neural Maximizes global sum rate. network (IFE-RNN). Each transmitter is equipped with deep reinforcement learning to make a
[19] different decision such as which user should be served and what the needed transmission power to mitigate interference.

A multi-agent deep reinforcement learning (MADRL) is proposed to

[20] reduce co-channel interference, this technique is based on the selection of autonomous channel and transmission power algorithms.

Improves the probability of successful transmission and the system throughput.

[21] Captures interference across different links through a proposed PowerNet leverages convolutional layers.

Enhances the system's energy efficiency. 
Table 1. Cont.

\begin{tabular}{|c|c|c|}
\hline & Interference Control Technique & Network Performance Achievement \\
\hline [22] & $\begin{array}{l}\text { Solves the problem of signal-to-interference-plus-noise by deep learning, } \\
\text { also formulates the joint design of interference coordination, power control, } \\
\text { and beamforming as a non-convex optimization problem. }\end{array}$ & $\begin{array}{l}\text { Improves the system's SINR and sum-rate } \\
\text { capacity. }\end{array}$ \\
\hline [23] & $\begin{array}{l}\text { Replaces the traditional receiver with a deep receiver to be able to recover } \\
\text { the transmitted information from the distorted sent data. }\end{array}$ & Decreases received signal bit error rate (BER). \\
\hline [24] & Controls the downlink transmission power through a base station. & $\begin{array}{l}\text { Enhance the system throughput and } \\
\text { decreases energy consumption. }\end{array}$ \\
\hline [25] & $\begin{array}{l}\text { Control the transmission power in the macro base station through Markov } \\
\text { decision process (MDP). }\end{array}$ & Maximizes sum spectrum efficiency. \\
\hline [26] & $\begin{array}{l}\text { Joint power control and channel selection optimization is implemented by } \\
\text { exploiting local information and outdated nonlocal information. }\end{array}$ & Maximizes system sum rate. \\
\hline [27] & $\begin{array}{l}\text { A power control algorithm based on multi-agent is proposed which is } \\
\text { designed to serve users by reusing the same spectrum band by deploying } \\
\text { multiple access points. }\end{array}$ & Enhance the overall networks sum rate. \\
\hline [28] & $\begin{array}{c}\text { A non-orthogonal multiple access (NOMA) downlink system based on } \\
\text { long-term resource allocation is formulated. }\end{array}$ & $\begin{array}{l}\text { Improves the network utility, queuing delay, } \\
\text { and average arriving rate. }\end{array}$ \\
\hline
\end{tabular}

Many articles have been proposed to enhance the communication between vehicles and everything (V2X), yet this issue has room for further investigation. These investigations must focus on how to increase the system's reliability and efficiency for providing efficient road traffic information and enhancing road safety. Therefore, Table 2 shows the comparison between the recently proposed methods and their effect on the system performance. Additionally, based on the comparison between the proposed models, the novelty and the importance of the proposed approach appeared. The proposed model controls the power of any interference devices to assure that the data sent between any vehicle $(V)$ and everything $(X)$ is accurate and efficient. Based on the interference power control, the data received by any destination is supposed to be approximate without interference, which affects the received signal. Additionally, based on the proposed approach, the V2X system is evaluated in terms of achievable data rate, packet delivery ratio, packet loss rate, and average end-to-end delay under different channel conditions.

Table 2. Comparison between the proposed approach and some different related works.

\begin{tabular}{|c|c|c|c|c|c|}
\hline & $\begin{array}{l}\text { Implemented } \\
\text { Technique }\end{array}$ & $\begin{array}{l}\text { Optimization } \\
\text { Problem }\end{array}$ & $\begin{array}{l}\text { Deep Learning } \\
\text { Method }\end{array}$ & $\begin{array}{l}\text { System Metrics } \\
\text { Evaluation }\end{array}$ & $\begin{array}{l}\text { Investigated } \\
\text { Scenario }\end{array}$ \\
\hline [4] & $\begin{array}{c}\text { Multi-hop relaying } \\
\text { between AV2X, direct } \\
\text { AV2X, and V2V } \\
\text { communications. }\end{array}$ & $\begin{array}{l}\text { Enhances system QoS } \\
\text { by finding the } \\
\text { optimum autonomous } \\
\text { inter-vehicle position } \\
\text { to communicate with } \\
\text { or to relay information } \\
\text { to any destination. }\end{array}$ & $\mathrm{N} / \mathrm{A}$ & $\begin{array}{c}\text { Best relay-vehicle } \\
\text { position between AV2X. } \\
\text { PDR. } \\
\text { Throughput. } \\
\text { Packet loss rate. } \\
\text { Average delivery } \\
\text { latency. }\end{array}$ & $\begin{array}{c}\text { Relaying } \\
\text { communication } \\
\text { between AV2X } \\
\text { with direct } \\
\text { communication } \\
\text { between V2V. }\end{array}$ \\
\hline [6] & $\begin{array}{c}\text { A combined } \\
\text { communication of V2I } \\
\text { with V2V is known as } \\
\text { cooperative } \\
\text { communication. }\end{array}$ & $\begin{array}{l}\text { Minimizes the overall } \\
\text { energy consumption } \\
\text { per bit given a target } \\
\text { for the outage } \\
\text { probability, } \\
\text { or maximizes the } \\
\text { system throughput. }\end{array}$ & $\mathrm{N} / \mathrm{A}$ & $\begin{array}{l}\text { Energy consumption. } \\
\text { Throughput. } \\
\text { Packet delivery ratio. } \\
\text { Packet loss rate. } \\
\text { Average } \\
\text { end-to-end-delay. }\end{array}$ & $\begin{array}{l}\text { Direct V2I } \\
\text { communication. } \\
\text { Multi-hop V2I } \\
\text { communication. } \\
\text { Cooperative V2I } \\
\text { communication. }\end{array}$ \\
\hline
\end{tabular}


Table 2. Cont.

\begin{tabular}{|c|c|c|c|c|c|}
\hline & $\begin{array}{l}\text { Implemented } \\
\text { Technique }\end{array}$ & $\begin{array}{l}\text { Optimization } \\
\text { Problem }\end{array}$ & $\begin{array}{l}\text { Deep Learning } \\
\text { Method }\end{array}$ & $\begin{array}{l}\text { System Metrics } \\
\text { Evaluation }\end{array}$ & $\begin{array}{l}\text { Investigated } \\
\text { Scenario }\end{array}$ \\
\hline [7] & $\begin{array}{l}\text { Power allocation } \\
\text { approach. }\end{array}$ & $\begin{array}{l}\text { Optimization of } \\
\text { energy efficiency. }\end{array}$ & $\mathrm{N} / \mathrm{A}$ & Energy efficiency & $\begin{array}{c}\text { Cellular } \\
\text { D2D-based V2X } \\
\text { communication } \\
\text { network. }\end{array}$ \\
\hline$[8]$ & $\begin{array}{l}\text { Non-orthogonal } \\
\text { multiple access } \\
\text { (NOMA) into } \\
\text { semi-president } \\
\text { scheduling. }\end{array}$ & $\begin{array}{l}\text { A joint-optimization } \\
\text { problem in terms of } \\
\text { user scheduling } \\
\text { indicators and power } \\
\text { allocation. }\end{array}$ & $\mathrm{N} / \mathrm{A}$ & $\begin{array}{c}\text { Minimize } \\
\text { semi-persistent } \\
\text { scheduling (SPS) period. }\end{array}$ & $\begin{array}{l}\text { mmWave-NOMA- } \\
\text { supported cellular } \\
\text { V2X system based } \\
\text { on signal cell. }\end{array}$ \\
\hline [13] & $\begin{array}{l}\text { A decentralized } \\
\text { algorithm based on } \\
\text { deep reinforcement } \\
\text { learning and Markov } \\
\text { decision process. }\end{array}$ & $\begin{array}{l}\text { A joint optimization } \\
\text { problem in terms of } \\
\text { resource allocation } \\
\text { and transmission } \\
\text { mode selection. }\end{array}$ & $\begin{array}{l}\text { Deep } \\
\text { reinforcement } \\
\text { learning }\end{array}$ & $\begin{array}{l}\text { Sum Capacity. } \\
\text { Satisfied rate. }\end{array}$ & $\begin{array}{l}\text { Cellular V2X } \\
\text { communication in } \\
\text { a vehicular } \\
\text { network. }\end{array}$ \\
\hline [14] & $\begin{array}{l}\text { A deep reinforcement } \\
\text { learning for a } \\
\text { security-aware } \\
\text { approach. }\end{array}$ & $\begin{array}{l}\text { Maximizes energy } \\
\text { efficiency (EE) and } \\
\text { spectral efficiency (SE) }\end{array}$ & $\begin{array}{l}\text { Deep } \\
\text { reinforcement } \\
\text { learning }\end{array}$ & $\begin{array}{l}\text { V2V spectral efficiency. } \\
\text { V2V energy efficiency. }\end{array}$ & $\begin{array}{l}\text { Cellular V2X } \\
\text { communication } \\
\text { networks. }\end{array}$ \\
\hline [15] & $\begin{array}{l}\text { Power control for two } \\
\text { different resource } \\
\text { allocation modes: } \\
\text { Scheduled resource } \\
\text { allocation model. } \\
\text { User equipment } \\
\text { autonomous resource } \\
\text { selection mode. }\end{array}$ & $\begin{array}{l}\text { Maximizes the } \\
\text { limitation of the } \\
\text { transmission power } \\
\text { for both users } \\
\text { vehicular and } \\
\text { pedestrian user } \\
\text { equipment. }\end{array}$ & $\mathrm{N} / \mathrm{A}$ & Spectral efficiency. & $\begin{array}{c}\text { V2X } \\
\text { communication } \\
\text { networks. }\end{array}$ \\
\hline [16] & $\begin{array}{l}\text { Multi-hop relaying } \\
\text { strategy. }\end{array}$ & $\mathrm{N} / \mathrm{A}$ & $\begin{array}{l}\text { Convolutional } \\
\text { neural network } \\
\quad(\mathrm{CNN}) .\end{array}$ & $\begin{array}{l}\text { Environmental } \\
\text { recognition } \\
\text { improvement. } \\
\text { Extend multi-hop } \\
\text { communication } \\
\text { reachability. }\end{array}$ & $\begin{array}{c}\text { V2X } \\
\text { communication } \\
\text { networks. }\end{array}$ \\
\hline [17] & $\begin{array}{l}\text { Distributed congestion } \\
\text { control based on deep } \\
\text { reinforcement } \\
\text { learning. }\end{array}$ & $\mathrm{N} / \mathrm{A}$ & $\begin{array}{l}\text { Deep } \\
\text { reinforcement } \\
\text { learning }\end{array}$ & $\begin{array}{l}\text { Channel busy ratio. } \\
\text { Packet delivery ratio. } \\
\text { Throughput. }\end{array}$ & $\begin{array}{l}\text { Cellular V2X } \\
\text { communication } \\
\text { networks. }\end{array}$ \\
\hline $\begin{array}{l}\text { Proposed } \\
\text { approach }\end{array}$ & $\begin{array}{l}\text { Interference power } \\
\text { control based on a } \\
\text { distributed deep } \\
\text { learning algorithm. }\end{array}$ & $\begin{array}{c}\text { Determine the } \\
\text { optimum required } \\
\text { interference power to } \\
\text { maximize V2X system } \\
\text { performance. }\end{array}$ & 1D- CNN & $\begin{array}{l}\text { Achievable data rate. } \\
\text { Packet delivery ratio. } \\
\text { Packet loss rate. } \\
\text { Average end-end-to } \\
\text { delay. }\end{array}$ & $\begin{array}{c}\text { V2X } \\
\text { communication } \\
\text { where the vehicles } \\
\text { in the road are } \\
\text { sharing } \\
\text { information with } \\
\text { everything. }\end{array}$ \\
\hline
\end{tabular}

Enhancing the connectivity between V2X for efficient road traffic information and road safety is a challenge that should be tackled. Different environmental conditions such as interference, path loss, and signal-to-interference-plus-noise-ratio (SINR) can affect V2X communication. In this work, the connectivity between vehicles $(\mathrm{V})$ and everything $(\mathrm{X})$ along with its characteristics is investigated to enhance communication between V2X. Therefore, the main contributions of the proposed approach can be listed as the following:

- An interference power control is developed through the proposed approach to enhance system performance in terms of achievable data rate, packet delivery ratio, packet loss rate, and average end-to-end delay for the V2X communication. 
- To ascertain that communication between V2X is reliable and efficient, an optimization problem using an analytical and deep learning model was developed. Based on the optimization model, the optimum required interference power $\left(P_{I}\right)$ is obtained to fulfill the required system QoS.

- A deep learning model is proposed and assessed, which employs 1D-CNN and dense layers, to calculate the required $P_{I}$. The model can be employed in the design stage for interference power control prediction and circumvention in real-life applications.

- The proposed approach is evaluated in terms of four metrics, which are achievable data rate, packet delivery ratio, packet loss rate, and average end-to-end delay under different channel conditions, such as vehicle transmission power $\left(P_{V}\right)$, required QoS, different $S I N R_{t h}$ values, path loss, and different transmission distances. Through these findings, the entire network can be optimized under different environmental conditions.

The following sections of this article are organized as follows. The proposed model, the optimization problem formulation, the dataset generation, and the deep learning algorithm of the proposed model are presented in Section 2. Assessing the deep learning model, simulation of the analytical, deep learning results, NS2 simulation results, and their discussions are provided in Section 3. Finally, the conclusion of this article is presented in Section 4.

\section{Material and Methods}

In this section, the analytical model of the proposed approach is established in terms of required interference transmission power $\left(P_{I}\right)$, achievable data rate, packet delivery ratio, packet loss rate, and average end-to-end delay in the context of a vehicular network. Based on the proposed approach, the communication between V2X could be established reliably and efficiently.

\subsection{Proposed Analytical Model}

A V2X communication system is considered, where information about traffic transfers from any moving vehicle to improve road safety and enhance traffic efficiency. The system, for any vehicle-to-everything pair $(\mathrm{V}, \mathrm{X})$, consists of several vehicles $(\mathrm{V})$, where $\mathrm{V} \varepsilon\{1, \ldots, n\}$, infrastructure, and interfering devices (I), where $\mathrm{I} \varepsilon\{1, \ldots, K\}$, as shown in Figure 1. The proposed model aims to find the interference transmission power $\left(P_{I}\right)$ with a given outage probability $\left(p_{\text {outV2X }}\right)$ target to enhance the system quality of service (QoS) by increasing the system overall system data rate $\left(R_{b V 2 X}\right)$, which in return increases packet delivery ratio and minimizes packet loss rate and average end-to-end delay, i.e.,

$$
\begin{array}{ll} 
& \operatorname{Max} \sum R_{b V 2 X} \\
\text { s.t. } & C 1:\left\{p_{\text {out } V 2 X} \leq 1-U\right\} \\
& C 2:\left\{P_{V} \leq P_{V \max }\right\}
\end{array}
$$

where $C 1$ and $C 2$ are the constraints of the optimization formulation problem. $C 1$ is considered that the V2X outage probability $\left(p_{o u t V 2 X}\right)$ must satisfy the required QoS $(U)$. $\mathrm{C} 2$ articulates the fact that the vehicle transmission power $\left(P_{V}\right)$ should not exceed the maximum vehicle transmission power $\left(P_{V \max }\right)$.

$U$ is the QoS of any V2X link, which can be expressed as:

$$
U=1-p_{\text {out } V 2 X}
$$




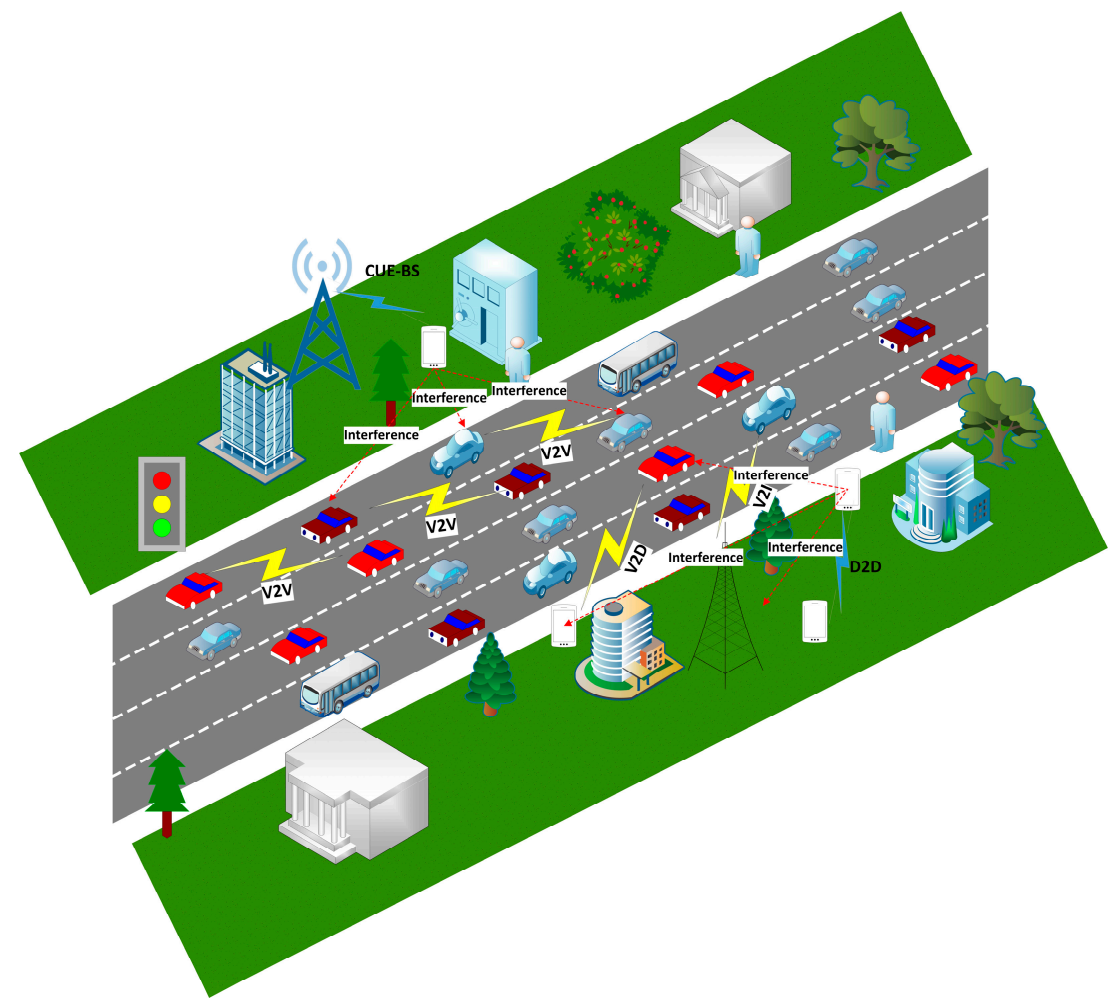

Figure 1. V2X communication.

The probability that the receiver has a signal-to-interference-plus-noise-ratio (SINR) less than the required signal-to-interference-plus-noise-ratio threshold $\left(S I N R_{t h}\right)$ is known as system outage probability, let $S I N R_{t h}$ refers to $\xi$. Therefore, $p_{\text {outV } 2 X}$ can be formulated as [29]:

$$
p_{\text {outV2X }}=p(\operatorname{SINR} \leq \xi)=1-\frac{P_{V}\left|h_{V 2 X}\right|^{2}}{\xi \sum_{i=1}^{K} P_{I}\left|h_{I i 2 X}\right|^{2}+P_{V}\left|h_{V 2 X}\right|^{2}} e^{-\frac{\xi N}{P_{V}\left|h_{V 2 X}\right|^{2}}}
$$

Assuming that $N \ll P_{V}\left|h_{V 2 X}\right|^{2}$, then Equation (3) can be rewritten as:

$$
p_{\text {out } 2 X}=1-\frac{P_{V}\left|h_{V 2 X}\right|^{2}}{\xi \sum_{i=1}^{K} P_{I}\left|h_{I i 2 X}\right|^{2}+P_{V}\left|h_{V 2 X}\right|^{2}}
$$

where $\left|h_{V 2 X}\right|^{2}$ and $\left|h_{I i 2 X}\right|^{2}$ are the channel gain coefficients between $\mathrm{V}$ and $\mathrm{X}$ and between any interfere device and $X$, which can be modeled as [30]:

$$
\begin{aligned}
\left|h_{V 2 X}\right|^{2} & =\frac{\left|h_{o V 2 X}\right|^{2}}{P L_{V 2 X}} \\
\left|h_{I i 2 X}\right|^{2} & =\frac{\left|h_{O I i 2 X}\right|^{2}}{P L_{I i 2 X}}
\end{aligned}
$$

Here, the noise power spectral density is denoted by $N$ is which is represented as $N=N_{o} B$, and the system bandwidth in Hertz is denoted by $B$. Moreover, $P_{I}$ represents the interference transmission power between any interference device and $X$. The parameters $\left|h_{o V 2 X}\right|^{2}$ and $\left|h_{O I i 2 X}\right|^{2}$ follow a complex normal distribution $\mathcal{C N} \sim(0,1) . P L_{V 2 X}$ and $P L_{I i 2 X}$ are the path loss between $\mathrm{V}$ and $\mathrm{X}$ and between any interference device and $\mathrm{X}$, respectively. where $P L_{V 2 X}$ and $P L_{I i 2 X}$ can be expressed as [30]:

$$
P L_{V 2 X}=\frac{1}{P L_{0 V 2 X} d_{V 2 X}{ }^{\alpha}}
$$




$$
P L_{\text {Ii } 2 X}=\frac{1}{P L_{o I i 2 X} d_{I i 2 X}^{\alpha}}
$$

where $P L_{O V 2 X}$ and $P L_{O I i 2 X}$ are the path loss constant between V2X and between any interfere transmitting and $X$, respectively. $d_{V 2 X}$ and $d_{I i 2 X}$ are the transmission distance between $V 2 X$ and the distance between any interfere transmitting and $X$, respectively. $\alpha$ is the path loss exponent.

In this work, the main objectives are to evaluate the efficiency and reliability of the proposed model in terms of achievable data rate, packet delivery ratio, packet loss rate, average end-to-end delay, and to optimize it under vibrant network conditions.

A vehicle network is considered where the transmission paths between any pair V-X are subjected to propagation path loss and narrowband Rayleigh fading with additive white Gaussian noise (AWGN) [31]. Moreover, the considered fading channel for different paths is assumed to be statistically mutually independent. The dedicated short-range communication (DSRC), a wireless standard, is considered the most promising protocol to be used for V2X communications. Specifically, for automotive use, the one-way or two-way short-range wireless communication channels can be involved, which is designed by DSRC technology [32]. For short-range communications, the $5.9 \mathrm{GHz}$ band has been allocated by The US Federal Communications Commission (FCC) to support wireless communication in the vehicular environment, including V2X [33]. The IEEE 802.11p standard has been employed by the MAC and physical layer of DSRC layered for vehicular communication. Furthermore, based on the orthogonal frequency division multiplexing (OFDM) method, eight different data rates can be supported by the IEEE 802.11p standard [34].

V2X Communication Scenario

The V2X scenario is shown in Figure 1, where vehicles are moving along a street and communicate with everything whether it is infrastructure, vehicles, or devices, the infrastructures are located on both sides of the road.

The frequency-flat block-fading Rayleigh channels are considered for uplink communications between vehicles and everything [31]. Thus, the overall achievable data rate $\left(R_{b V 2 X}\right)$ is expressed as:

$$
R_{b V 2 X}=B \log _{2}\left(1+\frac{P_{V}\left|h_{V 2 X}\right|^{2}}{\sum_{i=1}^{K} P_{I}\left|h_{I i 2 X}\right|^{2}+N}\right)
$$

The first-order optimality conditions are investigated to determine the solution of the optimization problem given in Equation (1). Therefore, the Lagrange optimization problem can be formulated as:

$$
L\left(R_{b V 2 X}, \lambda, \mu\right)=R_{b V 2 X}+\lambda\left(U-1+p_{o u t V 2 X}\right)+\mu\left(P_{V \max }-P_{V}\right)
$$

where $\lambda$ and $\mu$ should be non-negative values that represent the Lagrangian multipliers for $\mathrm{C} 1$ and $\mathrm{C} 2$, respectively.

The optimal solution to Equation (1) can be obtained by taking the derivative of Equation (10) with respect to $P_{V}$ and $P_{I}$, respectively, where it can be found as:

$$
\begin{gathered}
\frac{\partial L\left(R_{b V 2 X}, \lambda, \mu\right)}{\partial P_{V}}=0 \\
\mu=\left[\frac{B\left|h_{V 2 X}\right|^{2}}{\sum_{i=1}^{K} P_{I}\left|h_{I i 2 X}\right|^{2}+N+P_{V}\left|h_{V 2 X}\right|^{2}}\right]-\lambda\left[\frac{\left|h_{V 2 X}\right|^{2}}{\left(\xi \sum_{i=1}^{K} P_{I}\left|h_{I i 2 X}\right|^{2}+P_{V}\left|h_{V 2 X}\right|^{2}\right)}\right] \\
\frac{\partial L\left(R_{b V 2 X}, \lambda, \mu\right)}{\partial P_{I}}=0
\end{gathered}
$$




$$
\lambda=\frac{\left(\xi \sum_{i=1}^{K} P_{I}\left|h_{I i 2 X}\right|^{2}+P_{V}\left|h_{V 2 X}\right|^{2}\right) * B * \xi}{\left(\sum_{i=1}^{K} P_{I}\left|h_{I i 2 X}\right|^{2}+N\right)}
$$

Consequently, with taking the derivative of Equation (10) with respect to $\lambda$ and $\mu$, respectively, we find that:

$$
\begin{aligned}
& \frac{\partial L\left(R_{b V 2 X}, \lambda, \mu\right)}{\partial \lambda}=0 \\
& \frac{\partial L\left(R_{b V 2 X}, \lambda, \mu\right)}{\partial \mu}=0
\end{aligned}
$$

Then, based on Equation (15) and Equation (16), the two following propositions can be derived which are:

- Proposition 1 (Optimal interference transmission power): To maximize $R_{b V 2 X}$, the transmission power should be given by:

$$
P_{I}=\frac{P_{V}\left|h_{V 2 X}\right|^{2}(1-U)}{\xi \sum_{i=1}^{K}\left|h_{I i 2 X}\right|^{2} U}
$$

- Proposition 2 (Optimal vehicle transmission power): To maximize $R_{b V 2 X}$ when $\mathrm{V}$ communicates with $X$, the vehicle transmission power of any V2X link should be allocated as:

$$
P_{V}=P_{V \max }
$$

To evaluate the QoS of the proposed approach four different metrics have been considered:

1. Packet delivery ratio (PDR): PDR is known as the ratio of the successfully received packets (rp) when compared to the total number of sent packets (sp). The value of the packet delivery ratio always reflects how much the network is reliable. Hence, the increment of the sending packets means a relative increase in the receiving packets [35].

$$
\mathrm{PDR}=\frac{\# \mathrm{rp}}{\# \mathrm{sp}}
$$

2. Packet loss rate (PLR): PLR occurs when the sent packets fail to reach their destination. It is typically caused by an error in data transmission across the wireless network, or network congestion. Then, the packet loss rate can be calculated as the difference between the numbers of sent packets and received packets with respect to packets sent. Thus, it is defined by the Equation below [36]:

$$
\mathrm{PLR}=\frac{\# \mathrm{sp}-\# \mathrm{rp}}{\# \mathrm{sp}}
$$

3. Average end-to-end-delay (E2E): E2E is a networking term used to indicate any kind of delay and can be defined as the time needed for each transmitted packet to reach its destination; it is also called the network latency. Thus, it can be measured as the sum of the time needed to successfully send packets to the destination over the number of successfully received packets [35]:

$$
\mathrm{E} 2 \mathrm{E}=\frac{\sum_{\text {received packets }} \text { time spent to deliver packets }}{\# \mathrm{rp}}
$$

\subsection{Simulation of Analytical Model}

The proposed analytical problem illustrated in Section 2.1, was simulated using MAT$\mathrm{LAB}$ to visualize the effect of changing different influencing parameters and generating 
a dataset that is to be used to train a deep learning model. The simulation parameters applied are illustrated in Table 3. Different ranges of values were applied to the equations presented in Section 2.1, thus resulting in a dataset of 33,800 records. Each record represents an example of different combinations of the distance between $\mathrm{V}$ and $\mathrm{X}\left(d_{V 2 X}\right)$, the distance between the interfering devices I and $\mathrm{X}\left(d_{I 2 X}\right)$, vehicle transmission power $\left(P_{V}\right)$, the required signal-to-interference-plus-noise-ratio threshold $\left(S I N R_{t h}\right)$, the required quality of service $(U)$, and the resulting interference transmission power $\left(P_{I}\right)$.

Table 3. Network simulation parameters.

\begin{tabular}{|c|c|}
\hline Parameters & Value \\
\hline No & $-174 \mathrm{dBm}[15]$ \\
\hline$B$ & $10 \mathrm{MHz}$ [17] \\
\hline$P_{V \max }$ & $23 \mathrm{dBm}[17]$ \\
\hline Size of packet & 512 bytes \\
\hline$f_{c}$ & $5.9 \mathrm{GHz}$ \\
\hline Time for the simulation & $1000 \mathrm{Sec}$ \\
\hline Vehicles count & $100 \sim 250$ \\
\hline Velocity & $30 \sim 60 \mathrm{~km} / \mathrm{h}$ \\
\hline Traffic Agent & UDP \\
\hline MAC Protocol & IEEE $802.11 p$ \\
\hline Queue & PriQueue with size of 50 Packets \\
\hline Propagation mode & Two Ray Model \\
\hline Antenna & Omni-directional with a height of $1 \mathrm{~m}$ \\
\hline Routing Protocol & DSRC \\
\hline Seed count & 10 \\
\hline Type of Noise & AWGN \\
\hline$P L_{V 2 V}$ & $128.1+37.6 \log _{10}\left(d_{V 2 V}\right)[37]$ \\
\hline$P L_{V 2 I}$ & $128.1+37.6 \log _{10}\left(d_{V 2 I}\right)[37]$ \\
\hline
\end{tabular}

Table 4 shows the statistics calculated from the generated dataset for each input and the output $P_{I}$. The table shows the mean, standard deviation, minimum and maximum value of each parameter. The table shows that the range of the output parameter $P_{\mathrm{I}}$ varies between -16.1 and $46.84 \mathrm{dBm}$.

Table 4. Statistical analysis of the generated dataset.

\begin{tabular}{ccccccc}
\hline & $\boldsymbol{d}_{\boldsymbol{V} \mathbf{} \boldsymbol{X}}$ & $\boldsymbol{d}_{\boldsymbol{I 2 X}}$ & $\boldsymbol{P}_{\boldsymbol{V}}$ & $\boldsymbol{S I N R}_{\boldsymbol{t h}}$ & $\boldsymbol{U}$ & $\boldsymbol{P}_{\boldsymbol{I}}$ \\
\hline $\begin{array}{c}\text { Number of } \\
\text { records }\end{array}$ & 33,800 & 33,800 & 33,800 & 33,800 & 33,800 & 33,800 \\
\hline Mean & 61.237 & 122.473 & 20.567 & 10 & 0.702 & 16.944 \\
\hline $\begin{array}{c}\text { Standard } \\
\text { Deviation }\end{array}$ & 31.237 & 62.475 & 5.675 & 4.528 & 0.296 & 14.783 \\
\hline Minimum & 1 & 2 & 0 & 0 & 0.1 & -16.1 \\
\hline Maximum & 150 & 300 & 23 & 20 & 0.999 & 46.84 \\
\hline
\end{tabular}

Figure 2 displays the Pearson coefficients showing the correlation between all input and output parameters. The figure shows that the output $P_{I}$ has a high negative correlation with the $U$ parameter and a high positive correlation with the $P_{V}$ parameter yet, a low 
correlation with $d_{V 2 X}, d_{I 2 X}$, and $S I N R_{t h}$ parameters. Each of these parameters will have an influence that is to be learned by the deep learning model. The figure also shows that parameters $U$ and $P_{V}$ have a medium correlation to one another, thus providing some level of redundancy. Since the deep learning model attempts to resemble the human nervous system, having redundancy as a biological fundamental, it is acceptable to have partial redundancy within a deep learning model [38]. Furthermore, the authors in [39] proved that such redundancy tends to enhance the performance of neural-based models.

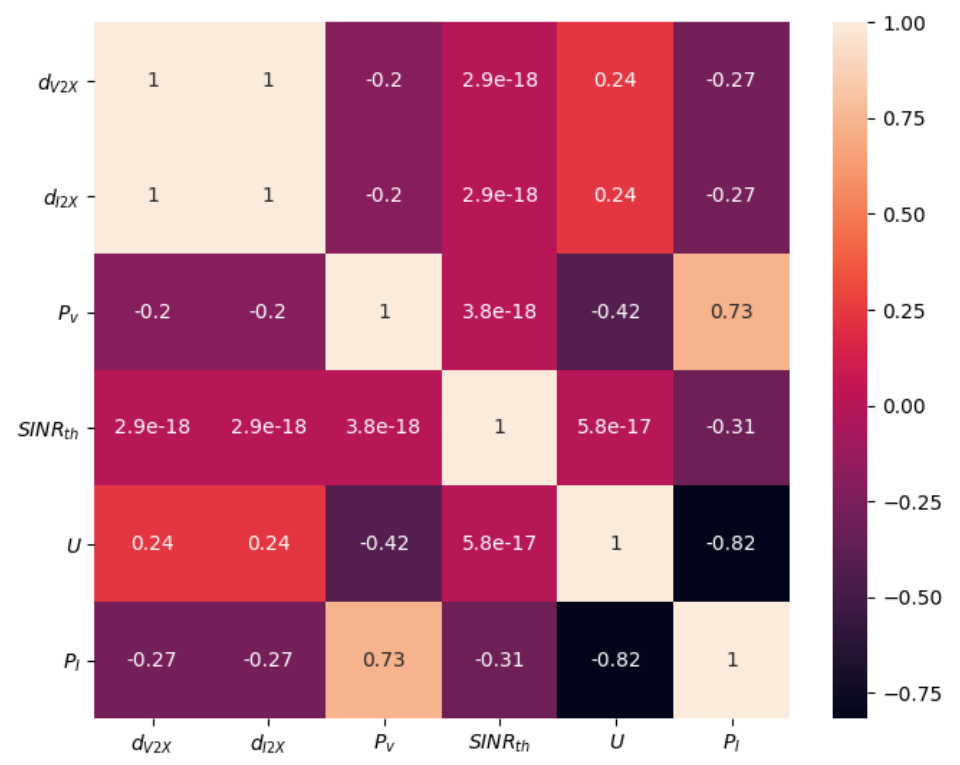

Figure 2. Pearson correlation coefficients of each input parameter $\left(d_{V 2 X}, d_{I 2 X}, P_{V}, S I N R_{t h}\right.$, and $\left.U\right)$ and the output $P_{I}$.

\subsection{Proposed Deep Learning Model}

In this section, a deep learning model is proposed and explained. Before inputting the variables into the proposed deep learning model, a normalization step is required to ease the learning stage of the model weights. The variables are all normalized using the min-max scaling method before being input into the model. The five variables $d_{V 2 X}, d_{I 2 X}$, $P_{V}, S I N R_{t h}$, and $U$ are input to the model and the output parameter $P_{I}$ is calculated from the final dense layer. The model consists of three types of phases: 1D-CNN, flattening, and dense layers, as shown in Figure 3. The normalized input parameters are passed through two 1D-CNN layers, first with 32 filters and a kernel of size 5 and the other with 16 filters and a kernel of size 1. Each 1D-CNN layer produces padded results to maintain the width of the output matrix. The output from the second 1D-CNN is then inputted to a flattening layer, which reforms the dimension, thus preparing it for input to the dense layers. Three dense layers follow the flattening layer, to output the regression result. The choice of the number of filters in the 1D-CNN and the number of nodes in the dense layers was based on a grid search to test for multiple combinations.

Considering the choice of activation functions, the grid search also involved testing the different methods that could follow the hidden layers in the proposed model. The best results were achieved when the output of each hidden layer was inputted to a parametric rectified linear unit (PReLU) activation function. For the final layer, the linear activation function was the suitable choice to adapt to the range of the $P_{I}$ previously shown in Table 4, since it ranges between -16.1 and $+46.84 \mathrm{dBm}$. 


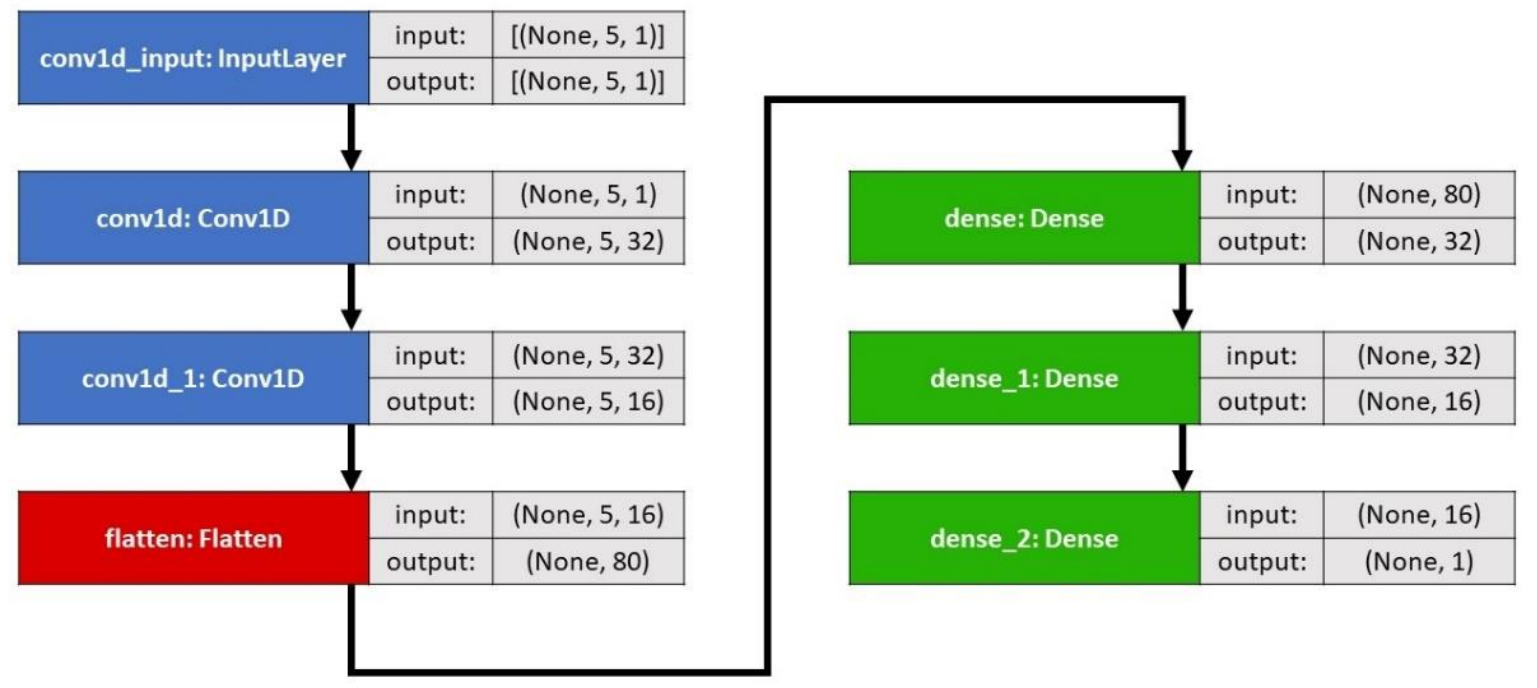

Figure 3. Proposed deep learning model.

The optimization used in the proposed model is the adaptive moment (Adam) as it can adaptively learn the required parameters according to the learning process [40]. Since the problem defined is a regression problem, the loss function used was to minimize the mean absolute error as the model learns. The experiments applied to train, test, and evaluate the proposed model will be explained in the following section.

\section{Results and Discussion}

In this section, the deep learning model assessment along with the analysis of the test results produced by the deep learning model versus that of the analytical analysis are presented. Furthermore, the performance of the proposed approach is examined through MATLAB and NS2 simulations in terms of optimum required interference power, reliability, and efficiency, which is presented by overall system achievable data rate, packet delivery ratio, packet loss rate, and average end-to-end delay.

\subsection{Deep Learning Model Assessment}

The proposed deep learning model previously explained in Section 2.3 was tested and evaluated in two experiments. The first experiment involved assessing the results compared to standard benchmarks such as linear, Adaboost, support vector, and multilayer perceptron regressors. The experiment involved splitting the data into 10-fold and calculating the average mean absolute error (MAE) and the average mean squared error (MSE) for all folds using the standard benchmarks and the proposed model. The 10 folds cross-validation assures that the model performs well given different data splits and is not biased to certain data distribution. The results produced by the proposed model outperformed the standard benchmarks, as shown in Table 5.

Table 5. Comparison between the results produced by the proposed model and standard benchmarks using 10-fold cross-validation.

\begin{tabular}{ccccc}
\hline & \multicolumn{2}{c}{ MAE } & \multicolumn{2}{c}{ MSE } \\
\hline & Train & Test & Train & Test \\
\hline Linear Regressor & 2.57 & 2.57 & 10.95 & 10.96 \\
\hline Adaboost Regressor & 1.85 & 1.86 & 5.86 & 5.91 \\
\hline Support Vector Regressor & 0.86 & 0.86 & 3.00 & 3.00 \\
\hline Multilayer Perceptron Regressor & 0.45 & 0.45 & 0.82 & 0.83 \\
\hline Proposed Model & 0.28 & 0.28 & 0.32 & 0.32 \\
\hline
\end{tabular}


The second experiment involved dividing the dataset into two parts, two-thirds of the records for training the model and one-third for testing. The reason for such a split was to be able to assess the results produced by a single trained model, thus resembling the real-life application with a single model on each device and perform a deep analysis by the output results, which will be presented in the following section. The model was trained for 400 epochs as shown in Figure 4. The figure shows that the change in error was minimal after epoch 250 thus suggesting that the model did not need further training after epoch 400 . The results produced when inputting the test data to this model will be presented and analyzed in the following section.

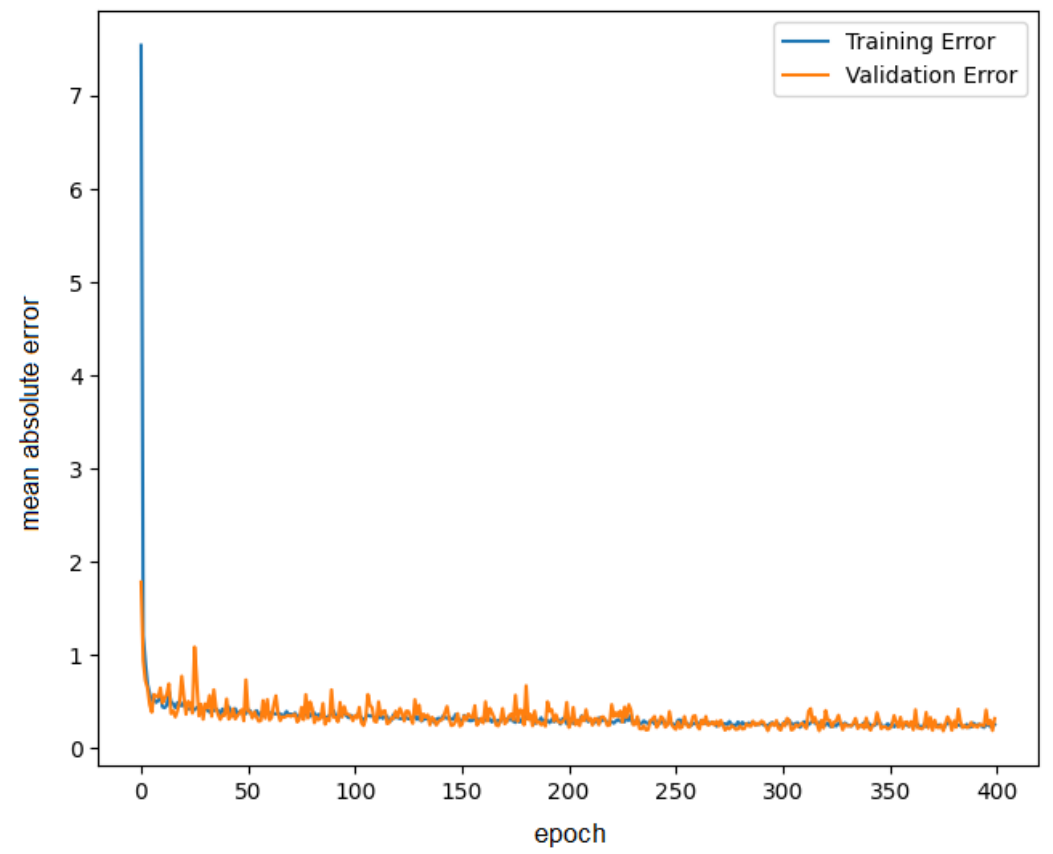

Figure 4. Training and validation mean absolute error generated during training the proposed model using two-thirds of the dataset.

\subsection{Analytical and Deep Learning Results}

In Figure 5, the optimum required interference power $\left(P_{I}\right)$ versus required system QoS is illustrated and compared with different $S_{I N R}$. Assuming that the transmission distance between $\mathrm{V}$ and $\mathrm{X}$ is $50 \mathrm{~m}$ and the vehicle transmission power is $23 \mathrm{dBm}\left(P_{V}\right)$. As it can be seen, the results obtained from the numerical and deep learning algorithm are identical for different $S I N R_{t h}$ and different required QoS.

Additionally, it can be mentioned that increasing $S_{I N R_{t h}}$ decreases the optimum required interference power to fulfill the required QoS. For example, when $S I N R_{t h}$ is $0 \mathrm{~dB}$ and the required QoS is 0.99 the optimum required interference power $\left(P_{I}\right)$ must be in the range of $17 \mathrm{dBm}$, while when SINR $R_{t h}$ increases, for example, $10 \mathrm{~dB}$ the interference power should be in the range of $7 \mathrm{dBm}$ to satisfy the required QoS, which is 0.99 . It is worth mentioning that reaching a QoS of 0.975 with the highest $\operatorname{SINR}_{t h}(20 \mathrm{~dB})$, as it is considered one of the highest network performance requirements, is required to control and reduce the interference power $\left(P_{I}\right)$ to the value of approximately $1.55 \mathrm{dBm}$. 


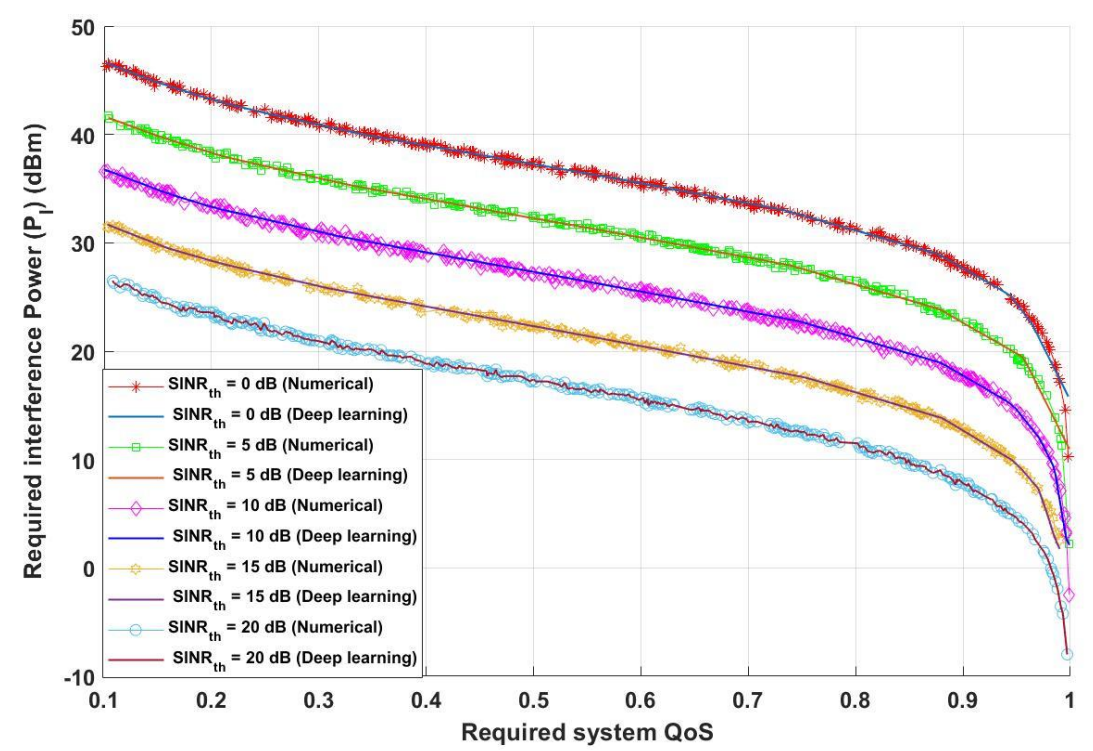

Figure 5. Required system QoS versus required interference power $\left(P_{I}\right)(\mathrm{dBm})$.

The required interference power $\left(P_{I}\right)$ needed to satisfy different required QoS versus transmission distances between $\mathrm{V} 2 \mathrm{X}$ is examined in Figure 6. It is assumed that the required $S I N R_{t h}$ is $10 \mathrm{~dB}$ and the vehicle transmission power $\left(P_{V}\right)$ is $23 \mathrm{dBm}$. Figure 6 depicts that increasing the QoS decreases the required interference power $\left(P_{I}\right)$ for both numerical and deep learning methods, which assures the result obtained in Figure 5. Additionally, it can be mentioned that the required interference power $\left(\mathrm{P}_{\mathrm{I}}\right)$ for each required QoS remains approximately the same when the transmission distance between V2X increases. This is because the system QoS is affected by different parameters, such as path loss and channel noise, which already exist during data transmission. Therefore, the required interference power $\left(P_{I}\right)$ should remain constant while increasing the transmission distance between V2X to overcome the side effect of other network conditions. It can be concluded from this figure that the required QoS is an important parameter that indicates how the system should deal with the interference power.

The overall achievable data rate for the proposed model is shown in Figure 7, with the same system parameters assumed in Figure 6. The proposed approach shows that for both numerical and deep learning methods, the system can always achieve the same achievable data rate with different required QoS. This is due to the interference power control provided using the proposed approach. It can be also mentioned that increasing the transmission distance decreases the overall achievable data rate; this is due to the other channel parameters that affect the system performance, such as path loss and channel noise.

The required interference power $\left(P_{I}\right)$ is evaluated once again in Figure 8 while monitoring the effect of changing the vehicle transmission power $\left(P_{V}\right)$. Assuming that the required $S I N R_{t h}$ is $10 \mathrm{~dB}$ and the required QoS is 0.99 . Figure 8 observes the interference power $\left(P_{I}\right)$ needed to fulfill the required system performance. It can be shown that increasing $P_{V}$ increases $P_{I}$ and leads to overcoming the interference power and enhancing system performance for numerical and deep learning methods. Additionally, the required $P_{I}$ remains constant when increasing the transmission distance between V2X, due to other factors that can affect the system performance, which requires having the same $P_{I}$ with transmission distance between V2X. Furthermore, it is worth mentioning from this figure that vehicle transmission power has an important role in decreasing the interference occurring at any transmission link. 


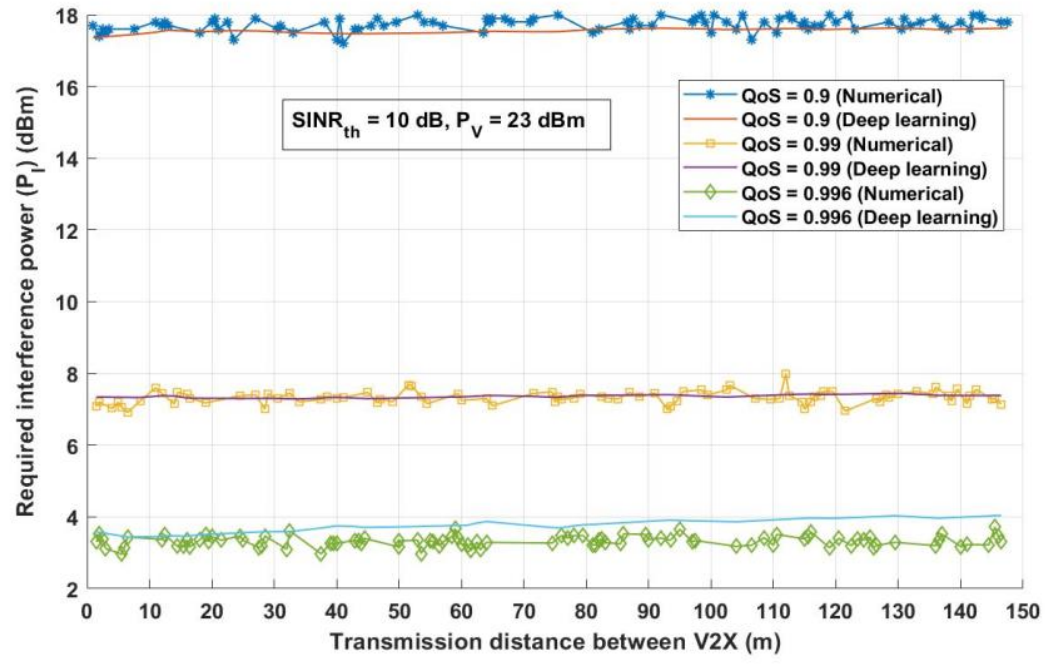

Figure 6. The transmission distance between $\mathrm{V} 2 \mathrm{X}(\mathrm{m})$ versus required interference power $\left(P_{I}\right)(\mathrm{dBm})$.

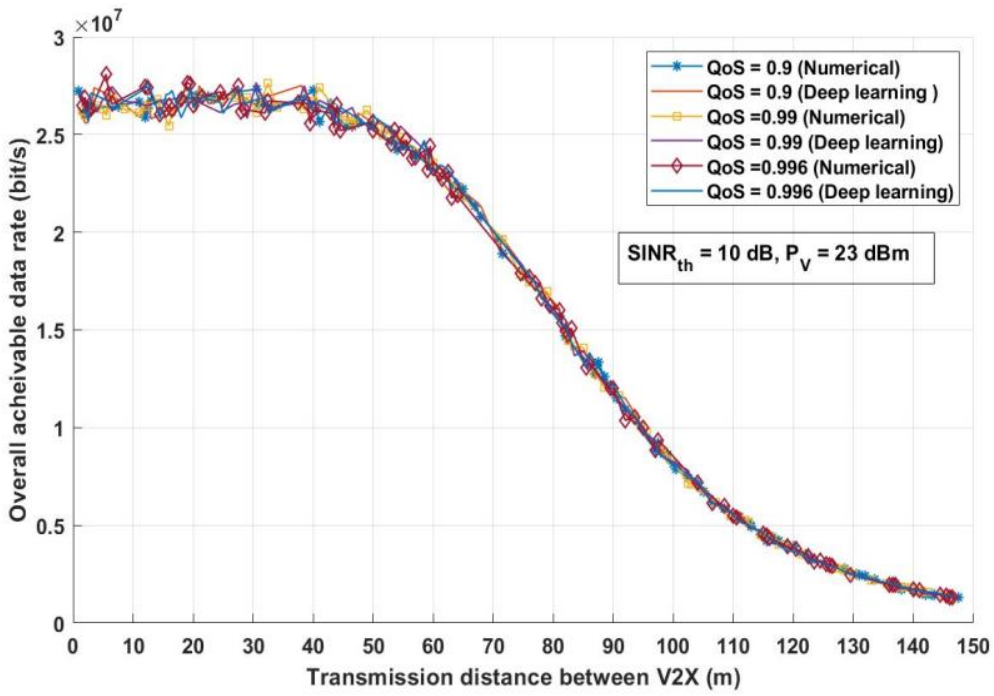

Figure 7. The transmission distance between V2X $(\mathrm{m})$ versus overall achievable data rate (bit/s).

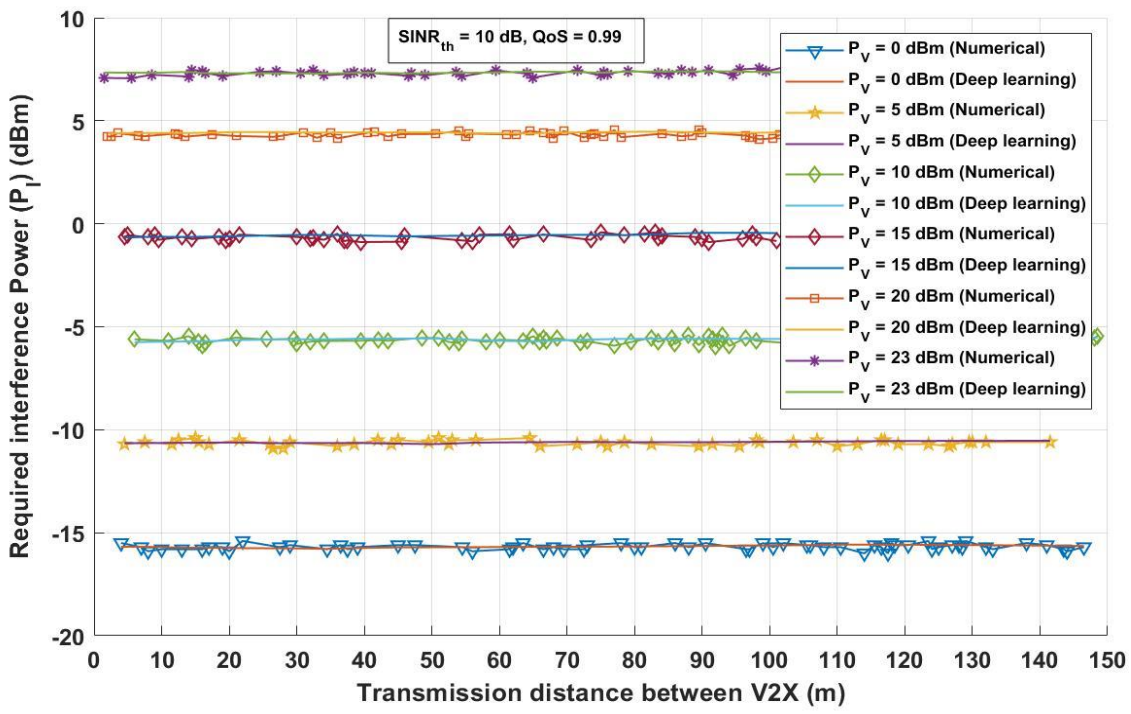

Figure 8. The transmission distance between V2X $(\mathrm{m})$ versus required interference power $\left(P_{I}\right)(\mathrm{dBm})$. 
Figure 9 demonstrates the performance of the previous scenario assumed in Figure 8 in terms of achievable data rate. It can be noted that for numerical and deep learning methods, the proposed approach can attain the same achievable data rate for different values of $P_{V}$. The obtained results show the ability of the proposed model to control the interference power to satisfy the required system performance. Additionally, it can be deduced that increasing the distance between V2X decreases the overall achievable data rate, which can be mainly affected by the path loss that increases with the increment of the transmission distance.

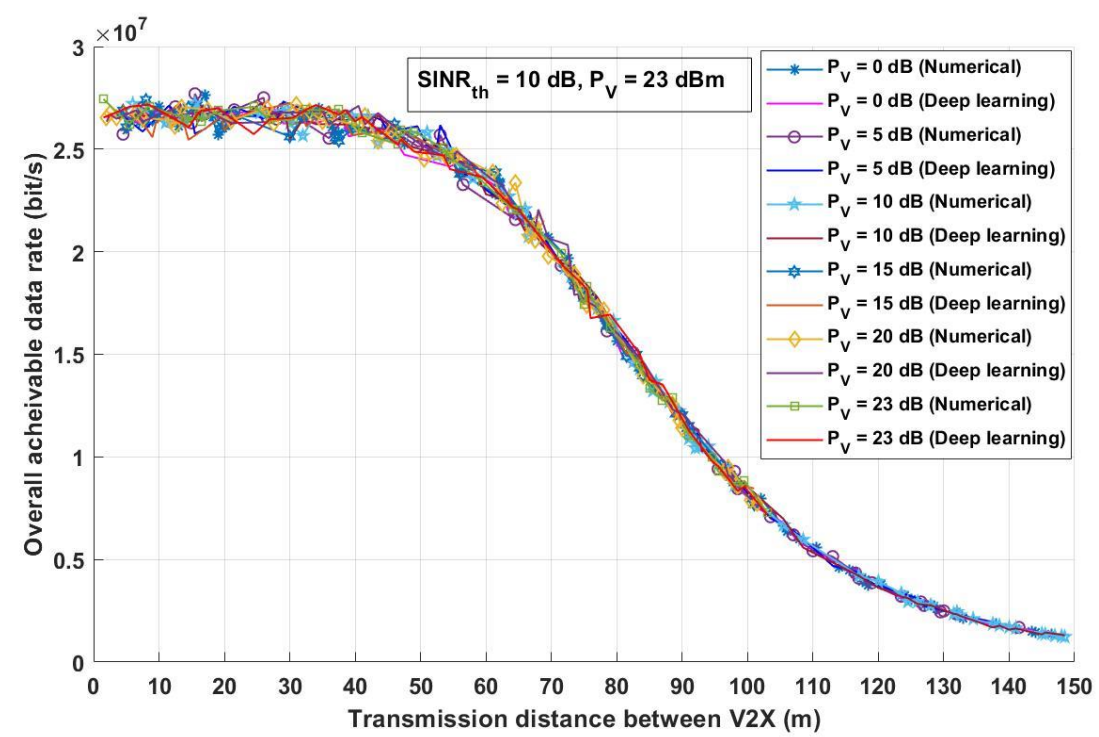

Figure 9. The transmission distance between V2X (m) versus overall achievable data rate (bit/s).

Figure 10 shows the required interference power $\left(P_{I}\right)$ versus vehicle transmission power $\left(P_{V}\right)$. Three transmission distances between V2X have considered to be $50 \mathrm{~m}, 100 \mathrm{~m}$, and $130 \mathrm{~m}$; it has also been assumed that $\operatorname{SINR}_{t h}$ is $10 \mathrm{~dB}$ and QoS is equal to 0.99 . It can be observed that increasing $P_{V}$ increases $P_{I}$ as when $P_{V}$ increases the system will be able to overcome the interference such that any interfering device can increase its transmission power when the main transmitting device has its maximum transmission power. Additionally, as discussed previously, increasing the transmission distance between V2X will not affect the required interference power but the main parameters that will affect the required interference power are the vehicle transmission and the required QoS.

Figure 11 depicts the effect of changing vehicle transmission power on the overall achievable data rate for three different transmission distances between V2X and with system parameters equal to $10 \mathrm{~dB}$ and 0.99 for $S_{I N R_{t h}}$ and QoS, respectively. It can be noticed from Figure 11 that, to achieve the maximum achievable data rate, each transmission distance $\left(d_{V 2 X}\right)$ will need an optimum vehicle transmission power $\left(P_{V}\right)$. For example, when $d_{V 2 X}$ is $50 \mathrm{~m}$ the maximum achievable data rate can be obtained when $P_{V}$ is $2 \mathrm{dBm}$. Alternatively, when $d_{V 2 X}$ is $100 \mathrm{~m}$, the required $P_{V}$ is between 9 and $11 \mathrm{dBm}$ to attain the maximum, while when increasing $d_{V 2 X}$ to $130 \mathrm{~m}$ the required $P_{V}$ is $23 \mathrm{dBm}$, which is the maximum vehicle transmission power. It can be concluded from this figure that the maximum achievable data rate cannot always be achieved by the maximum vehicle transmission power but it can be achieved based on system parameters and QoS requirements, which by default affect the required value of vehicle transmission power $\left(P_{V}\right)$ and the required interference power $\left(P_{I}\right)$. 


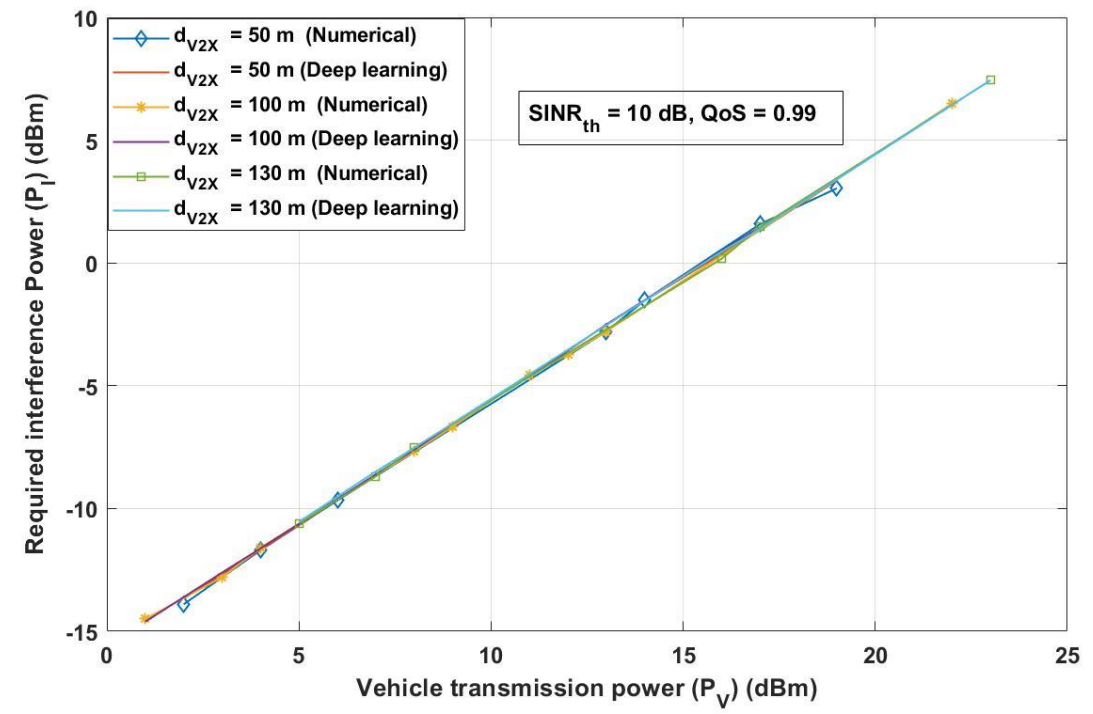

Figure 10. Vehicle transmission power $\left(P_{V}\right)(\mathrm{dBm})$ versus required interference power $\left(P_{I}\right)(\mathrm{dBm})$.

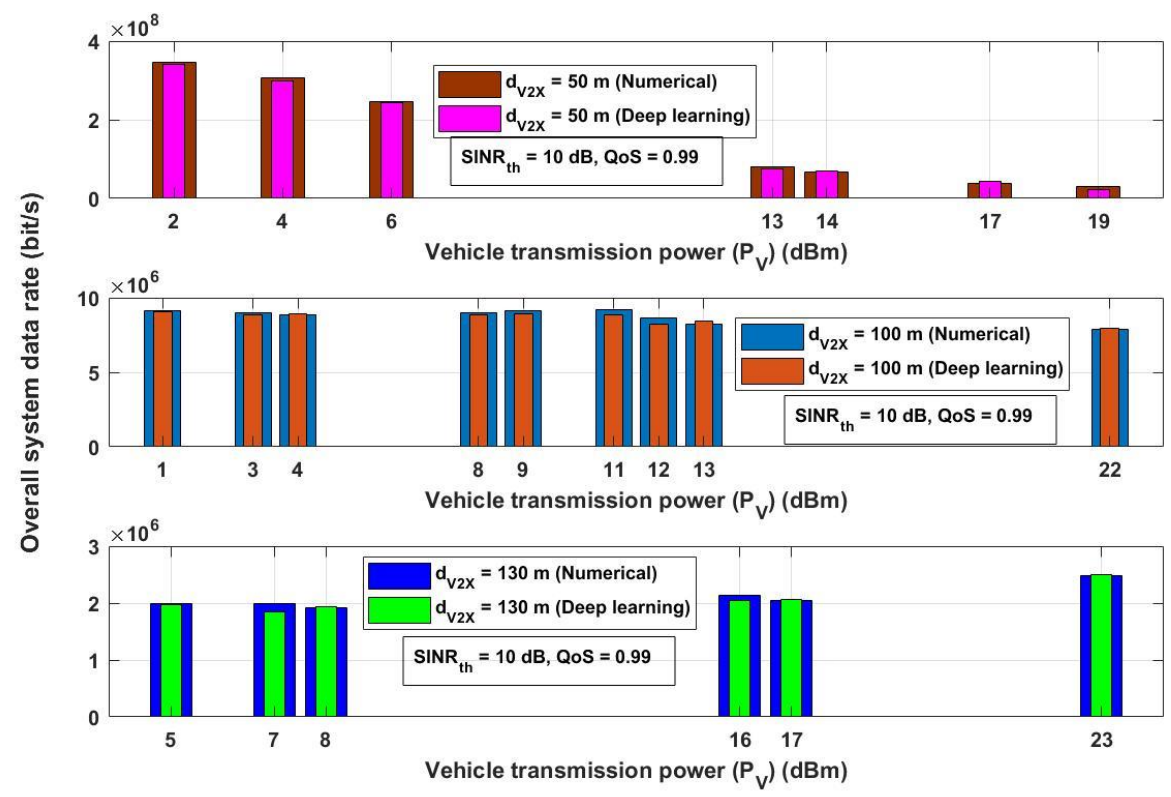

Figure 11. Vehicle transmission power $\left(P_{V}\right)(\mathrm{dBm})$ versus overall achievable data rate $(\mathrm{bit} / \mathrm{s})$.

\subsection{NS2 Simulation Results}

Network Simulator version 2 (NS2) is an event-driven tool deployed for the simulation of wired and wireless network operations and protocols (such as transport layer and routing protocols). Its flexibility, modularity, open-source availability, mechanism modifiability (based on users' preferences), stability, and extensibility have led to its popularity in the network research community. Community researchers and developers are continually working on the enhancement of NS2 [41,42]. Consequently, NS2 is used to simulate the model proposed in this research work.

In the proposed model, it is assumed that all vehicles are keeping a safe distance from each other. In most countries, to ensure road safety and reduce the possibility of collision, as a general guideline, a sufficient distance must be kept between each driver's vehicle and the one in front of him/her. The $2 \mathrm{~s}$ rule is often used as a rule of thumb and is being taught at driving schools as the minimum distance that should be maintained between two vehicles. According to [43], the safe distance between every two vehicles can vary between 
1 and $2 \mathrm{~s}$ assuming ideal conditions, according to the rules of different countries. Regarding the standard lane width, [44] stated that lane width for any road ranges from 3.0 to $3.5 \mathrm{~m}$.

Therefore, in the proposed model, it is assumed that all vehicles are moving at varying speeds ranging from $30 \mathrm{~km} / \mathrm{h}$ to $60 \mathrm{~km} / \mathrm{h}$, the road width is $3.5 \mathrm{~m}$, and the distance between any two consecutive vehicles follows the $2 \mathrm{~s}$ rule. The network parameters used for simulation are listed in Table 3. Vehicles' mobility patterns were generated using NS2. Moreover, for system performance evaluation, AWK scripts were used to obtain packet delivery ratio (PDR) as shown in Figure 12, packet loss rate (PLR) as shown in Figure 13, and average end-to-end delay (E2E) as shown in Figure 14. In Figures 12-14, the simulation results were reported by assuming different counts of vehicles ranging from 100 to 250. In each figure, the results of two models were compared: a model without interference power control and a model with interface power control (proposed model).

According to Figure 12, when the interference power control is not applied, it can be observed that the PDR has increased almost linearly as the number of vehicles increased. This can be justified by the following. As the number of vehicles increases, they tend to get out of the range of the interference sources, which allows more packets to successfully reach the destination, with minimal packet loss, thus increasing the PDR. However, when interference power control is imposed (proposed model), the PDR tends to remain almost constant with minimal changes. The vehicles experience minimum interference due to power control, thus allowing packets to successfully arrive at their destinations. As the number of vehicles increase, the PDR will not vary as all vehicles are experiencing minimum interference, which ensures the delivery of generated packets with minimal losses.

Similarly, in Figure 13, when interference power control is not imposed, the PLR tends to decrease almost linearly as opposed to a nearly constant PLR with minimal variation when the proposed model is applied. In case of no interference control, the greater number of vehicles, the higher the number of vehicles outside the range of interference, thus fewer packets being lost due to interference and less PLR being recorded. In the proposed model, the reported PLR does not vary with the increase in the number of vehicles because the vehicles are already experiencing minimal interference. Therefore, the PLR will not vary as more vehicles are introduced. Figures 12 and 13 show the sustainability of the proposed model as more vehicles are introduced, the PDR and PLR are not significantly affected compared to the model with the absence of interference power control.

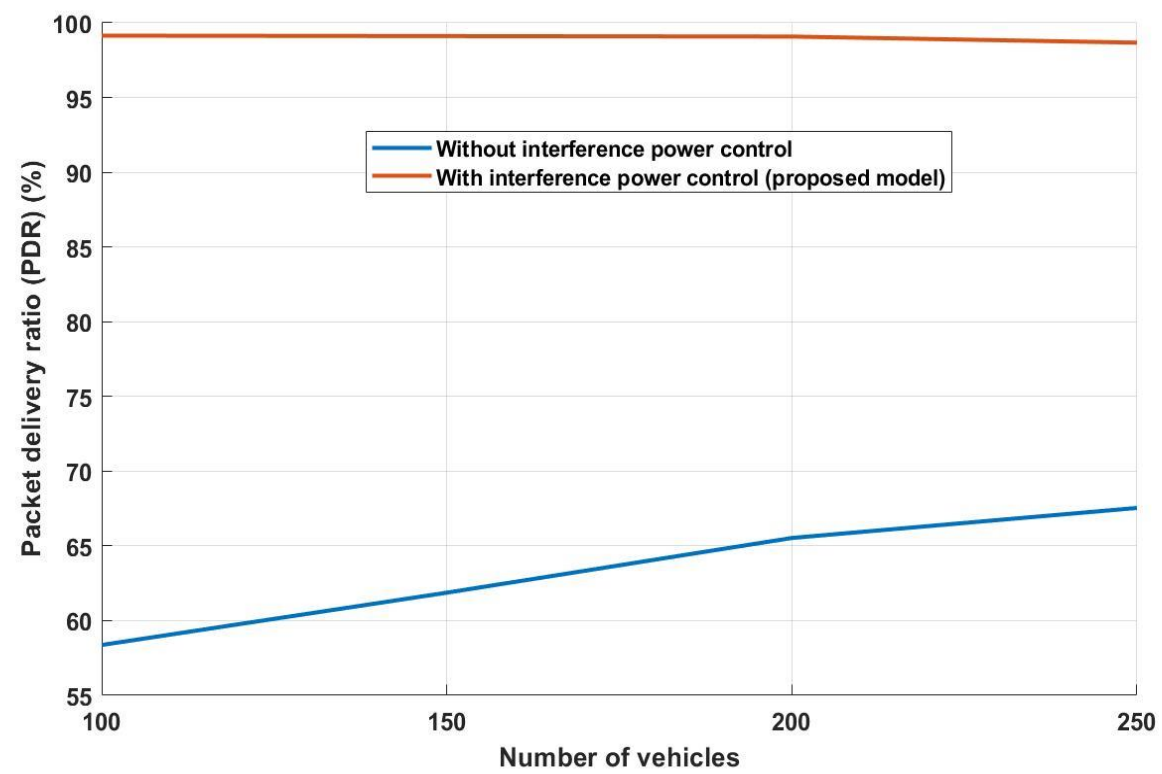

Figure 12. Packet delivery ratio (PRD) (\%) versus the number of vehicles. 


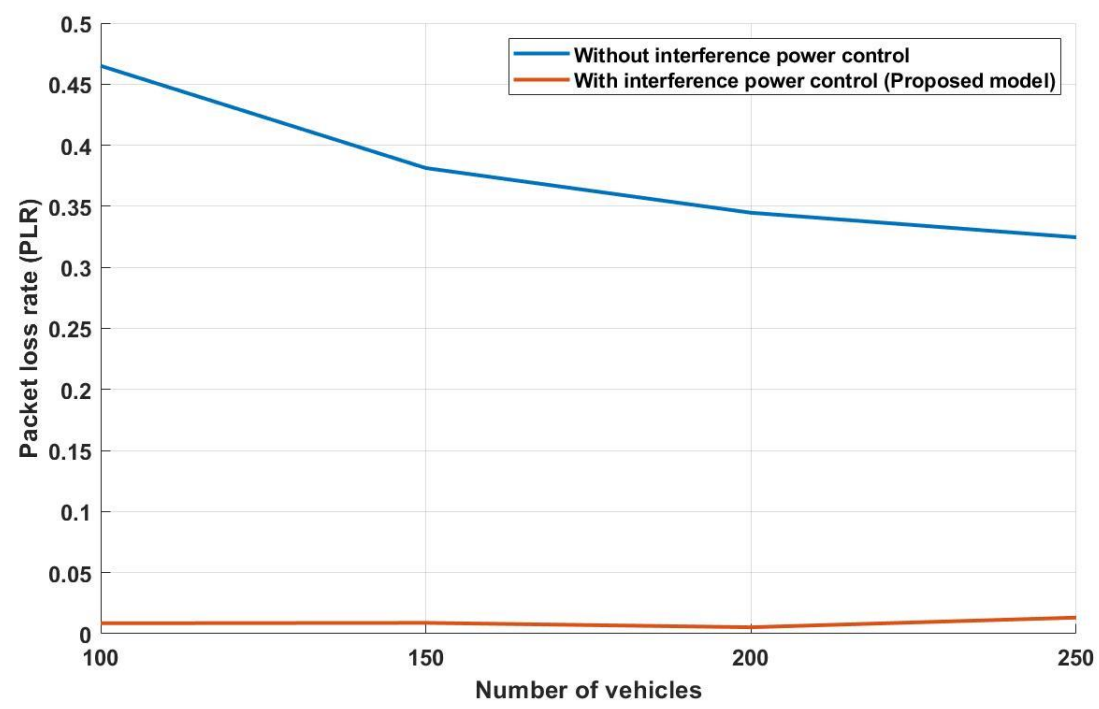

Figure 13. Packet loss rate (PLR) versus the number of vehicles.

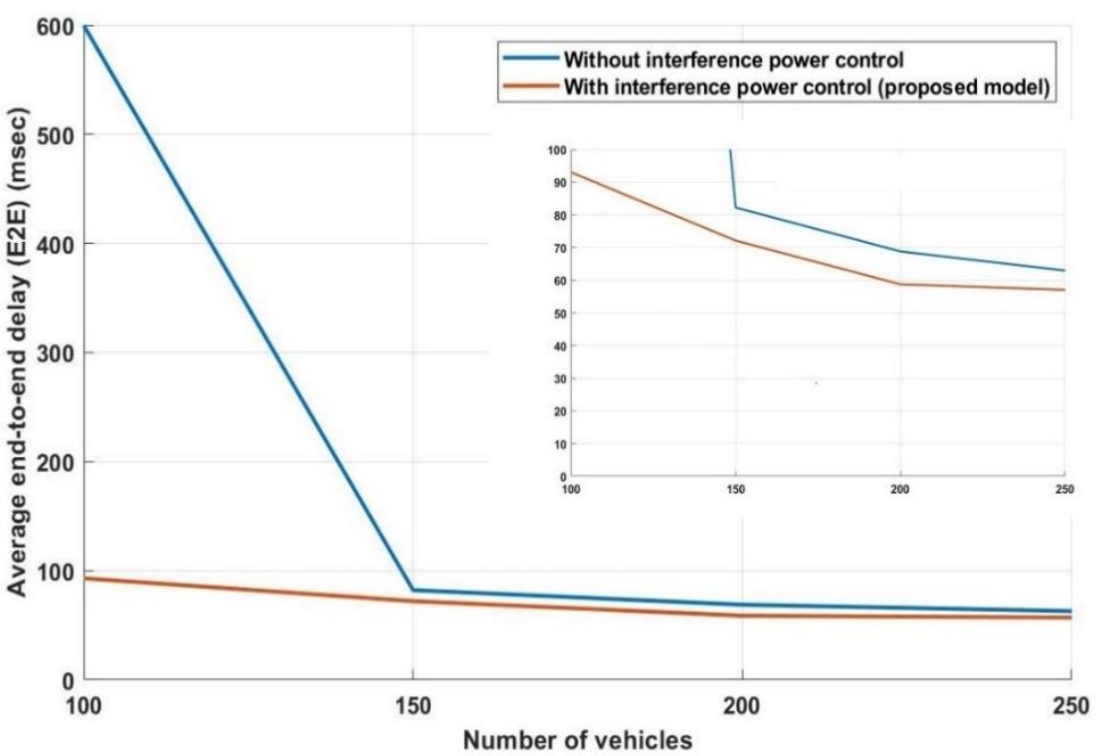

Figure 14. Average end-to-end delay (E2E) (msec) versus the number of vehicles.

Figure 14 depicts the E2E reported against the number of vehicles. When no interference power control is applied, the E2E significantly decreases as the number of vehicles increases until the number of vehicles reaches 150 , then the decrease is almost linear. The steep decline in the E2E is due to the increased number of vehicles getting away from the range of the interference nodes, allowing packets to be delivered with minimal delay and retransmissions. However, when the proposed model is applied, the vehicles are already experiencing minimal interference, allowing the packets to be delivered with minimal delay. It is worth mentioning that decreasing the interference power decreases the required retransmission time as the channel performance is enhanced, thus decreasing the E2E.

Clearly, to enhance the system performance and achieve the preferable QoS as clarified in this paper, optimum required interference transmission power $\left(P_{I}\right)$ should be indicated based on the system conditions such as the outage probability, $P_{\text {out }}$, vehicle transmission power $\left(P_{V}\right)$, and required signal-interference-plus-noise-ratio $\left(S I N R_{t h}\right)$. The results of this proposed model can help decide how and when the connection between V-X should be employed to have a proper connection that improves system performance and enhances the reception of road traffic information and increases road safety. 


\section{Conclusions}

An interference power control model for V2X based on a deep learning algorithm was proposed to enhance the connectivity between $\mathrm{V}$ and $\mathrm{X}$, thus providing efficient road traffic communications. The proposed model is expressed using the Lagrange optimization technique to determine the optimum required interference power, thus satisfying the system requirements. Based on this optimization model, the system QoS was evaluated in terms of reliability and effectiveness for V2X communications. Furthermore, a 1D-CNN deep learning model was proposed to calculate the optimum interference transmission power $\left(P_{I}\right)$ in real-life applications. The proposed deep learning model was compared to standard benchmarks in a 10-fold cross-validation split and provided an improvement in terms of mean absolute error. Moreover, further assessment of the model was performed to compare it to the analytical model. It has been shown that the optimum required interference power can vary under certain environmental conditions such as the outage probability, vehicle transmission power, path loss, and $S I N R_{t h}$. The proposed model can be identified given the optimum required interference power in a vehicular network. The findings of this work can be used to enhance the efficiency and reliability of the vehicular network for improving road traffic information and increasing road safety under different environmental conditions. The results showed that the proposed control interference power can dynamically achieve the preferable QoS, in terms of achieving the highest achievable data rate, packet delivery ratio with the lower possible packet loss rate, and average end-to-end delay.

Author Contributions: Conceptualization, R.A.O.; data curation, R.A.O.; formal analysis, R.A.O., S.N.S., and Y.N.M.S.; investigation, R.A.O. and S.N.S.; methodology, R.A.O. and S.N.S.; resources, R.A.O., S.N.S., Y.N.M.S., and M.N.E.; software, R.A.O. and S.N.S.; validation, R.A.O. and S.N.S.; visualization, R.A.O., S.N.S., and Y.N.M.S.; writing—original draft, R.A.O., S.N.S., Y.N.M.S., and M.N.E.; writing-review and editing, R.A.O., S.N.S., Y.N.M.S., and M.N.E. All authors have read and agreed to the published version of the manuscript.

Funding: This research received no external funding.

Informed Consent Statement: Not applicable.

Data Availability Statement: Not applicable.

Conflicts of Interest: The authors declare no conflict of interest.

\section{References}

1. Ahangar, M.N.; Ahmed, Q.Z.; Khan, F.A.; Hafeez, M. A survey of autonomous vehicles: Enabling communication technologies and challenges. Sensors 2021, 21, 706. [CrossRef] [PubMed]

2. Sedar, R.; Kalalas, C.; Vázquez-Gallego, F.; Alonso-Zarate, J. Intelligent Transport System as an Example of a Wireless IoT System. In Wireless Networks and Industrial IoT; Springer: Cham, Switzerland, 2021; pp. 243-262.

3. Gohar, A.; Nencioni, G. The Role of 5G Technologies in a Smart City: The Case for Intelligent Transportation System. Sustainability 2021, 13, 5188. [CrossRef]

4. Osman, R.A.; Abdelsalam, A.K. A Novel Adaptive Approach for Autonomous Vehicle Based on Optimization Technique for Enhancing the Communication between Autonomous Vehicle-to-Everything through Cooperative Communication. Appl. Sci. 2021, 11, 9089. [CrossRef]

5. Moubayed, A.; Shami, A.; Heidari, P.; Larabi, A.; Brunner, R. Edge-enabled V2X service placement for intelligent transportation systems. IEEE Trans. Mob. Comput. 2020, 20, 1380-1392. [CrossRef]

6. Osman, R.A.; Peng, X.-H.; Omar, M.A. Adaptive cooperative communications for enhancing QoS in vehicular networks. Phys. Commun. 2018, 34, 285-294. [CrossRef]

7. Xiao, H.; Zhu, D.; Chronopoulos, A.T. Power allocation with energy efficiency optimization in cellular D2D-based V2X communication network. IEEE Trans. Intell. Transp. Syst. 2019, 21, 4947-4957. [CrossRef]

8. Wang, B.; Shi, R.; Shi, F.; Hu, J. mmWave-NOMA-based low-latency and high-reliable communications for enhancement of V2X services. IEEE Access 2020, 8, 57049-57062. [CrossRef]

9. Kiranyaz, S.; Ince, T.; Hamila, R.; Gabbouj, M. Convolutional neural networks for patient-specific ECG classification. In Proceedings of the 37th Annual International Conference of the IEEE Engineering in Medicine and Biology Society (EMBC), Milan, Italy, 25-29 August 2015; pp. 2608-2611. 
10. Kiranyaz, S.; Avci, O.; Abdeljaber, O.; Ince, T.; Gabbouj, M.; Inman, D.J. 1D convolutional neural networks and applications: A survey. Mech. Syst. Signal Process. 2020, 151, 107398. [CrossRef]

11. Osman, R.A.; Saleh, S.N.; Saleh, Y.N. A Novel Interference Avoidance Based on a Distributed Deep Learning Model for 5G-Enabled IoT. Sensors 2021, 21, 6555. [CrossRef]

12. Lee, H.; Lee, S.H.; Quek, T.Q. Deep learning for distributed optimization: Applications to wireless resource management. IEEE J. Sel. Areas Commun. 2019, 37, 2251-2266. [CrossRef]

13. Zhang, X.; Peng, M.; Yan, S.; Sun, Y. Deep-reinforcement-learning-based mode selection and resource allocation for cellular V2X communications. IEEE Internet Things J. 2019, 7, 6380-6391. [CrossRef]

14. Liu, Z.; Han, Y.; Fan, J.; Zhang, L.; Lin, Y. Joint optimization of spectrum and energy efficiency considering the c-v2x security: A deep reinforcement learning approach. In Proceedings of the 2020 IEEE 18th International Conference on Industrial Informatics (INDIN), Warwick, UK, 20-23 July 2020; Volume 1, pp. 315-320.

15. Li, X.; Ma, L.; Shankaran, R.; Xu, Y.; Orgun, M.A. Joint power control and resource allocation mode selection for safety-related V2X communication. IEEE Trans. Veh. Technol. 2019, 68, 7970-7986. [CrossRef]

16. Morocho-Cayamcela, M.E.; Lee, H.; Lim, W. Machine learning to improve multi-hop searching and extended wireless reachability in V2X. IEEE Commun. Lett. 2020, 24, 1477-1481. [CrossRef]

17. Choi, J.-Y.; Jo, H.-S.; Mun, C.; Yook, J.-G. Deep Reinforcement Learning-Based Distributed Congestion Control in Cellular V2X Networks. IEEE Wirel. Commun. Lett. 2021, 10, 2582-2586. [CrossRef]

18. Shi, J.; Zhang, Q.; Liang, Y.-C.; Yuan, X. Distributed Deep Learning for Power Control in D2D Networks with Outdated Information. IEEE Trans. Wirel. Commun. 2021, 20, 5702-5713. [CrossRef]

19. Naderializadeh, N.; Sydir, J.J.; Simsek, M.; Nikopour, H. Resource management in wireless networks via multi-agent deep reinforcement learning. IEEE Trans. Wirel. Commun. 2021, 20, 3507-3523. [CrossRef]

20. Zhao, J.; Zhang, Y.; Nie, Y.; Liu, J. Intelligent resource allocation for train-to-train communication: A multi-agent deep reinforcement learning approach. IEEE Access 2020, 8, 8032-8040. [CrossRef]

21. Zhang, T.; Mao, S. Energy-efficient power control in wireless networks with spatial deep neural networks. IEEE Trans. Cogn. Commun. Netw. 2019, 6, 111-124. [CrossRef]

22. Mismar, F.B.; Evans, B.L.; Alkhateeb, A. Deep reinforcement learning for 5G networks: Joint beamforming, power control, and interference coordination. IEEE Trans. Commun. 2019, 68, 1581-1592. [CrossRef]

23. Zheng, S.; Chen, S.; Yang, X. DeepReceiver: A deep learning-based intelligent receiver for wireless communications in the physical layer. IEEE Trans. Cogn. Commun. Netw. 2020, 7, 5-20. [CrossRef]

24. Xiao, L.; Zhang, H.; Xiao, Y.; Wan, X.; Liu, S.; Wang, L.-C.; Poor, H.V. Reinforcement learning-based downlink interference control for ultra-dense small cells. IEEE Trans. Wirel. Commun. 2019, 19, 423-434. [CrossRef]

25. Wang, C.; Deng, D.; Xu, L.; Wang, W.; Gao, F. Joint Interference Alignment and Power Control for Dense Networks via Deep Reinforcement Learning. IEEE Wirel. Commun. Lett. 2021, 10, 966-970. [CrossRef]

26. Tan, J.; Liang, Y.-C.; Zhang, L.; Feng, G. Deep reinforcement learning for joint channel selection and power control in D2D networks. IEEE Trans. Wirel. Commun. 2020, 20, 1363-1378. [CrossRef]

27. Zhang, L.; Liang, Y.-C. Deep Reinforcement Learning for Multi-Agent Power Control in Heterogeneous Networks. IEEE Trans. Wirel. Commun. 2020, 20, 2551-2564. [CrossRef]

28. Sun, Y.; Wang, Y.; Jiao, J.; Wu, S.; Zhang, Q. Deep learning-based long-term power allocation scheme for NOMA downlink system in S-IoT. IEEE Access 2019, 7, 86288-86296. [CrossRef]

29. Kim, M.; Lee, J. Impact of an interfering node on unmanned aerial vehicle communications. IEEE Trans. Veh. Technol. 2019, 68, 12150-12163. [CrossRef]

30. ElHalawany, B.M.; Ruby, R.; Wu, K. D2D communication for enabling Internet-of-Things: Outage probability analysis. IEEE Trans. Veh. Technol. 2019, 68, 2332-2345. [CrossRef]

31. Wang, S.; Wang, D.; Li, C.; Xu, W. Full duplex AF and DF relaying under channel estimation errors for V2V communications. IEEE Access 2018, 6, 65321-65332. [CrossRef]

32. Wu, X.; Subramanian, S.; Guha, R.; White, R.G.; Li, J.; Lu, K.W.; Bucceri, A.; Zhang, T. Vehicular communications using DSRC: Challenges, enhancements, and evolution. IEEE J. Sel. Areas Commun. 2013, 31, 399-408.

33. Kiela, K.; Barzdenas, V.; Jurgo, M.; Macaitis, V.; Rafanavicius, J.; Vasjanov, A.; Kladovscikov, L.; Navickas, R. Review of V2X-IoT standards and frameworks for ITS applications. Appl. Sci. 2020, 10, 4314. [CrossRef]

34. Yang, Y.; Fei, D.; Dang, S. Inter-vehicle cooperation channel estimation for IEEE 802.11 p V2I communications. J. Commun. Networks 2017, 19, 227-238. [CrossRef]

35. Alkhalifa, I.S.; Almogren, A.S. NSSC: Novel segment based safety message broadcasting in cluster-based vehicular sensor network. IEEE Access 2020, 8, 34299-34312. [CrossRef]

36. Da Silva, C.A.G.; Pedroso, C.M. Mac-layer packet loss models for wi-fi networks: A survey. IEEE Access 2019, 7, $180512-180531$. [CrossRef]

37. Liu, Z.; Chan, K.Y.; Ma, K.; Guan, X. Chance-constrained optimization in D2D-based vehicular communication network. IEEE Trans. Veh. Technol. 2019, 68, 5045-5058. [CrossRef]

38. Nguyen, A.T.; Xu, J.; Luu, D.K.; Zhao, Q.; Yang, Z. Advancing system performance with redundancy: From biological to artificial designs. Neural Comput. 2019, 31, 555-573. [CrossRef] 
39. Johnson, M.; Chartier, S. Is There a Purpose to Network Redundancy? In Proceedings of the 2018 International Joint Conference on Neural Networks (IJCNN), Rio de Janeiro, Brazil, 8-13 July 2018; pp. 1-8.

40. Kingma, D.P.; Ba, J. Adam: A method for stochastic optimization. arXiv 2014, preprint, arXiv:1412.6980.

41. Issariyakul, T.; Hossain, E. Introduction to network simulator 2 (NS2). In Introduction to Network Simulator NS2; Springer: Boston, MA, USA, 2009; pp. 1-18.

42. Kumar, K.R.; Karyemsetty, N.; Samatha, B. Performance Analysis of Vehicular Network Scenarios Using SUMO and NS2 Simulators. In Data Engineering and Communication Technology; Springer: Singapore, 2021; pp. 337-344.

43. Breyer, G. Safe Distance between Vehicles. Available online: https://www.cedr.eu/docs/view/60794fa6cf0c0-en (accessed on 28 November 2021).

44. Guideline, L.W. Version 2.0, City of Toronto, Transportation Services. Available online: https://www.toronto.ca/wp-content/ uploads/2017/11/921b-ecs-specs-roaddg-Lane_Widths_Guideline_Version_2.0_Jun2017.pdf (accessed on 1 September 2021). 